ORIGINAL ARTICLE

\title{
Examining child restraint use and barriers to their use: lessons from a pilot study
}

\author{
J C Simpson, J Wren, D J Chalmers, S C R Stephenson
}

Injury Prevention 2003;9:326-331

\begin{abstract}
Objective: To determine the suitability of four research methods to measure the rate of child restraint device (CRD) use and incorrect use in New Zealand and obtain data on barriers to CRD use.

Design and setting: To assess the rates of CRD use among vehicles carrying children 8 years of age and under, two methods were piloted-namely, an unobtrusive observational survey and a short interview and close inspection. A self administered questionnaire and focus group interviews were also piloted to assess CRD use, reasons for use and non-use, and to obtain information on barriers to their use. Respondents to all methods except the focus groups were approached in supermarket car park sites at randomly selected times. Focus groups were established with parents identified through early childhood organisations. All methods were assessed on criteria related to efficiency, representativeness, and ability to obtain the necessary data.

Results: The observational survey provided a simple method for identifying rates of CRD use, while the self administered questionnaire obtained data on demographic characteristics and reported the installation and use/non-use of CRDs. The interview/inspection addressed all the questions of both the above methods and enabled incorrect CRD use to be examined. The focus groups provided the most meaningful information of all methods on barriers to CRD use.

Discussion and conclusion: Advantages and limitations of these methods are discussed and some refinements of the original instruments are proposed. The interview/inspection and focus group methods were identified as being more appropriate for efficiently obtaining reliable data on CRD use and identification of barriers to CRD use.
\end{abstract}

See end of article for authors' affiliations

Ms Jean C Simpson, Injury Prevention Research Unit University of Otago, PO Box 913, Dunedin, New Zealand; jean.simpson@ ipru.otago.ac.nz

l New Zealand, as in other "wealthy" nations, motor vehicle traffic crashes continue to be a leading cause of child injury mortality. ${ }^{1}$ Kypri et al, for example, reported motor vehicle occupant death rates of 5.7/100 000 per year for infants and 3.7/100 000 per year for children aged 1-4 years for the years 1986-95. ${ }^{2}$ They identified that at least $27 \%$ of infants who died as occupants in motor vehicle traffic crashes were unrestrained.

Child restraint device (CRD) use in motor vehicles has been compulsory in New Zealand since 1994, yet an observational study undertaken by the New Zealand Land Transport Safety Authority (LTSA) in 2000 found that in some regions compliance was as low as $64 \%{ }^{3}$ Even if CRDs are in use, they may be incorrectly installed or children may not be properly seated in them. Estimates of the proportion of CRDs incorrectly used, ranging from $30 \%-80 \%$, have been reported for other industrialised nations. ${ }^{4-11}$ Incorrect use may nullify the effectiveness of the CRDs. ${ }^{9}$

With the exception of the observational surveys undertaken by the LTSA, there has been no published research on CRD use or barriers to their use in New Zealand since the early 1980s. ${ }^{12-16}$ Findings from these earlier studies identified two categories of non-use: driver attitudes and design problems. ${ }^{14-17}$ In the 1990s, a North American study found that drivers were dissatisfied with CRD design, particularly the mechanisms for installing CRDs in vehicles. ${ }^{18}$

A national survey has been proposed to determine current levels of CRD use, correct and incorrect, and the barriers to their use in New Zealand. To identify the best methods for collecting such data the following pilot study was undertaken. A variety of techniques utilised in previous studies were incorporated including close inspection, self report questionnaires, pictograms, short interviews, and focus groups. ${ }^{4-11}{ }^{17}$

This paper reports on four methods piloted, namely, an unobtrusive observational survey, a short interview with close inspection, a self administered questionnaire, and a series of focus groups. These are assessed with respect to efficiency, ability to collect the necessary data, and representativeness.

\section{METHODS}

An unobtrusive observational survey (subsequently called the observational survey) and a short interview with close inspection (interview/inspection) were undertaken to investigate the rate of correct and incorrect use of CRDs. Both the interview/inspection and a self administered questionnaire (questionnaire) were used to obtain information on the use and non-use of CRDs and barriers to CRD use. Focus groups were conducted to elicit detailed information particularly on the barriers to use. These methods were piloted in Dunedin, New Zealand, a city with a population of approximately 100000.

The observational survey, interview/inspection, and questionnaire were conducted in six randomly selected food supermarket car parks. In New Zealand, grocery shopping is commonly undertaken at supermarkets, with customers using private vehicles. These sites were considered less likely to produce a socioeconomically biased sample than sites such as early childcare centres, schools, or fast food outlets used in previous studies. ${ }^{5} 1819$ The methods were conducted sequentially over seven weeks by observers operating in teams of two. These observers were trained in interview technique and correct fitting of CRDs. Data collection times were randomly assigned during three days each week with equal numbers of hours spent in each car park. All privately owned vehicles in

Abbreviations: CRD, child restraint device; LTSA, Land Transport Safety Authority 
which children 8 years or younger were occupants were eligible for selection.

The variables measured by each method are listed in table 1 . In the observational survey, data were recorded as vehicles slowed to enter the car park. Initially in the interview/inspection, potential respondents were approached and invited to participate as they parked their vehicle. Some children were releasing themselves from their CRD as the vehicle was parked, however, so this procedure was modified and potential participants were approached as they returned to their vehicle after shopping. Similarly the self administered questionnaire and a return envelope were distributed to prospective participants as they returned to their vehicles after shopping. Contact details were obtained to enable potential participants to be followed up by phone or letter.

The questions used in the interview sought basic demographic information on drivers and children, and ownership, installation, non-use and ease of use, of the CRDs. They were based on those used in studies undertaken by Geddis et al in the 1980s. ${ }^{12-15}$ To explore whether there was a link between incorrect CRD use and the design of imported Japanese vehicles that dominate second hand vehicle sales in New Zealand, an additional question was asked regarding the country of manufacture..$^{20}$ In the inspection, the CRD was examined with respect to its fit in the vehicle and the placement of the child in the CRD. ${ }^{11}$ In both the observational survey and the interview/inspection, pictures or diagrams of a variety of CRDs (pictograms) were provided to assist in identifying the type of CRD used and its correct installation. ${ }^{8}$ The questionnaire consisted of predominantly closed questions similar to those in the interview. Information on use and non-use of CRDs was sought using a five point scale to assess disagreement/agreement on a series of statements.

Focus groups were recruited through registered early childhood organisations selected at random from a comprehensive list of such organisations. An experienced facilitator (the first author) conducted the semistructured interviews on use of CRDs and barriers to their use. These lasted between 45 and 90 minutes, were recorded on audiotape, and subsequently transcribed and analysed inductively for themes and associated dimensions. ${ }^{21-23}$

Elements related to the three criteria, efficiency, ability to collect data, and representativeness, were used to assess the viability of these methods for a national study. In gauging efficiency, the response rate, the time required to collect data and material, and the human resources needed were considered. The ability of the methods to collect the necessary information was determined by comparing the variables collected by each, and assessing whether the level of detail was sufficient for the study's purpose. Because demographic characteristics of the population of parents or caregivers with young children who drive cars were not available, a reference population was identified using the 2001 census. ${ }^{24}$ National census data show that $90 \%$ of parents whose youngest child is between $0-9$ years are aged between $20-44$ years. ${ }^{24}$ The reference population identified consisted of adults aged 2044 years domiciled in urban Dunedin. Reference variables used were gender, age, and education levels. A comparison of household incomes between respondents to each method and the reference population was not possible, as age specific household income data for Dunedin were not available. The reference population for this variable included all age groups in the Dunedin population. The proportion of incorrect use among respondents to the interview/inspection was calculated as the proportion of drivers who made at least one error in fitting the CRD or placing the child in the CRD.

\section{RESULTS}

\section{Efficiency}

The number of respondents participating in each method and where applicable, the response rate, are reported in table 2. The drivers who declined to participate in the interview/ inspection stated a lack of time as their reason for noninvolvement. The self administered questionnaire was dis-

\begin{tabular}{|c|c|c|c|c|}
\hline Variables & $\begin{array}{l}\text { Observational } \\
\text { survey } \\
\text { (observation) }\end{array}$ & $\begin{array}{l}\text { Interview/inspection } \\
\text { (observation/ } \\
\text { inspection/self report) }\end{array}$ & $\begin{array}{l}\text { Self administered } \\
\text { questionnaire } \\
\text { (self report) }\end{array}$ & $\begin{array}{l}\text { Focus group } \\
\text { (self report) }\end{array}$ \\
\hline \multicolumn{5}{|l|}{ Drivers } \\
\hline Sex & Estimate & Yes & Yes & Yes \\
\hline Age & Estimate & Yes & Yes & Yes \\
\hline Ethnicity & No & Yes & Yes & Yes \\
\hline Education & No & Yes & Yes & Yes \\
\hline Household income & No & Yes & Yes & Yes \\
\hline Seat belt use & Yes & Yes & No & No \\
\hline Relationship to child(ren) & No & Yes & Yes & Yes \\
\hline \multicolumn{5}{|l|}{ Vehicles } \\
\hline Type & Yes & Yes & Yes & No \\
\hline Make & Yes & Yes & Yes & No \\
\hline Where manufactured & No & Yes & No & No \\
\hline \multicolumn{5}{|l|}{ Children } \\
\hline Age & Estimate & Yes & No & No \\
\hline Sex & Estimate & Yes & No & No \\
\hline Number in household & No & No & Yes & No \\
\hline \multicolumn{5}{|l|}{ CRD use } \\
\hline Position in car & Yes & Yes & No & No \\
\hline Type & Yes & Yes & No & No \\
\hline Ownership & No & Yes & Yes & Yes \\
\hline Frequency of removal & No & Yes & Yes & Yes \\
\hline Ease of use & No & Yes & Yes & Yes \\
\hline Fitting in vehicle examined & No & Yes & No & No \\
\hline Placement of child examined & No & Yes & No & No \\
\hline Reasons for non use & No & Yes & Yes & Extensive \\
\hline Barriers to use & No & Limited & Limited & Extensive \\
\hline $\begin{array}{l}\text { Potential to give rate of use } \\
\text { of CRD }\end{array}$ & Yes & Yes & No & No \\
\hline
\end{tabular}




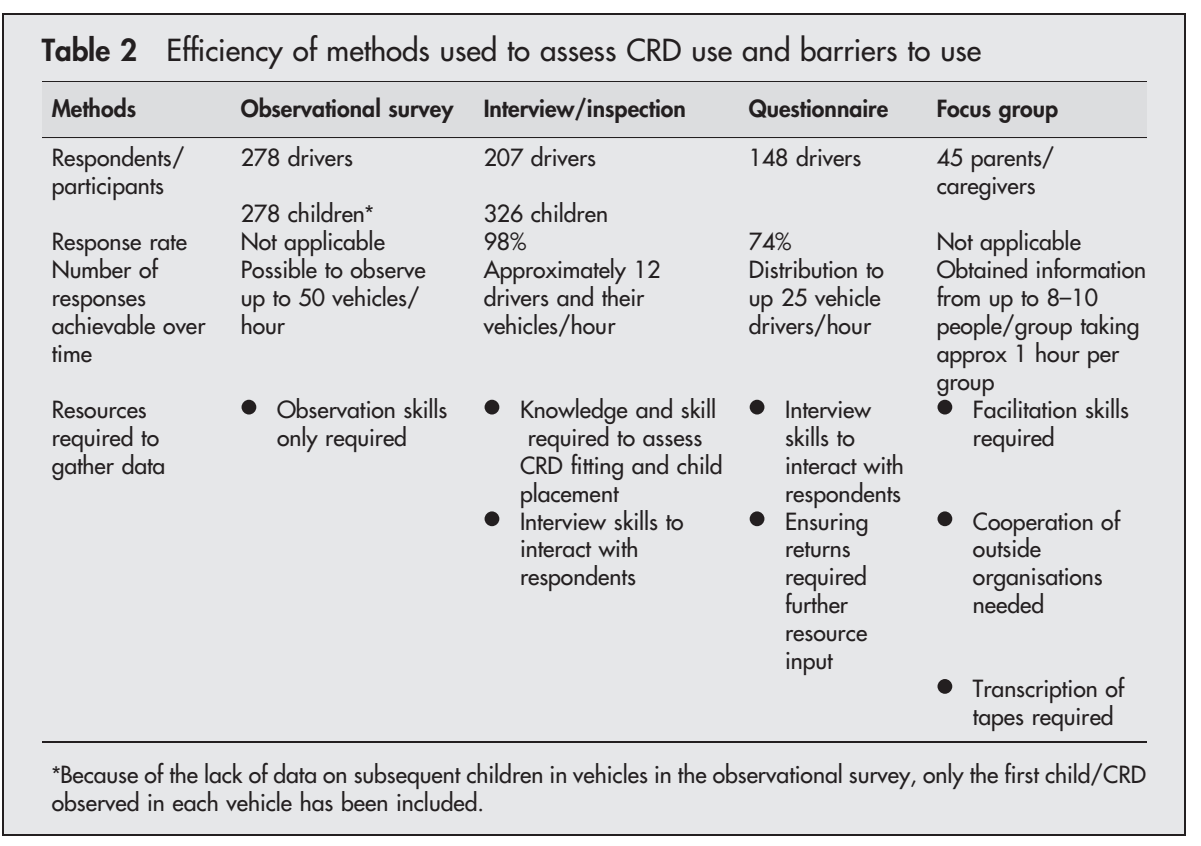

tributed to 200 drivers. Of the 148 who responded, $20 \%$ required a follow up phone call or letter to obtain their response.

Of the three methods based in the car parks, the interview/ inspection required the most time to accomplish. It also required the field workers to have considerable knowledge of CRDs, and skill in interviewing. Less time and fewer skills were required to undertake the observational survey or distribute the questionnaire. Data collection per vehicle was fastest in the observational survey. There were some limitations with all methods. For example, the flow of eligible vehicles using the car parks directly affected the speed of data collection in these settings. In the fourth method, each of the eight focus groups took approximately an hour to conduct. They required good facilitation skills, the cooperation and coordination of outside organisations, and resources for transcribing audiotapes.

\section{Data collection}

A summary of the results obtained from the observational survey, interview/inspection and questionnaire is presented in table 3. The interview/inspection provided the most comprehensive coverage of information sought. There was consistency between the three sets of data, with some exceptions. For example, in the observational survey, the age of the first child observed in each car could be estimated in $98 \%$ of the cases and the sex in $74 \%$, but data on age and sex were missing for subsequent children in many of the vehicles. Consequently, only data on the first child observed in the survey were included in the results reported. Other exceptions were: (a) the different distributions for position of CRDs in vehicles, (b) the lack of information on CRDs from the observational survey, and (c) the lack of information on CRDs in vehicles from the questionnaire.

Information was sought on the ease of CRD use, correct and incorrect use, barriers to use, and reasons for non-use. Both the interview/inspection and questionnaire reported on drivers' perceptions of the ease of use of CRDs. Only in the interview/inspection could errors in CRD use be observed. These related to installing the CRD in the vehicle, and placing the child in the CRD. Results from the interview/inspection indicated that although $62 \%$ of drivers interviewed considered that it was "very easy" to fit the CRD in the vehicle, 75\% of drivers made at least one error using a CRD. Sixty five percent of drivers made errors seating the child in the restraint and $61 \%$ made errors installing the CRD in the vehicle. The most common errors observed, the failure to use a top tether strap and the failure to secure the harness tension strap ends, have been classified previously as serious errors. ${ }^{11}$ The data collection forms were reported to be easy to use by the interviewers, although the pictograms did not aid the inspection process as the detail was insufficient for the range of CRDs being used among the respondents.

Despite participants in the focus groups exhibiting a high level of willingness to use CRDs, their discussions generated more information on barriers to CRD use than attributes of CRDs. A number of problems related to the ease of use were identified: operational barriers, bulk, difficulty in fitting, and lack of authoritative instruction, both for the legal responsibilities and fitting. Other types of barriers were also noted, for example, the cost of CRDs or of modifying a vehicle to fit a CRD, and social barriers, such as children exerting pressure on parents to use a booster seat or adult seatbelt before they were physically ready.

In the interview/inspection and questionnaire, reasons why children were not restrained were obtained by asking respondents to select from a list of predetermined options, and an "other" category. Eighty two percent of respondents in the interview/inspection and $72 \%$ of those from the questionnaire considered the question did not apply to them as they did not recall their children having been unrestrained in a vehicle in the last six months. In both methods, key reasons for non-use given by those who did respond were: not enough room to fit the CRD, the child self releasing from the CRD, and driving another car that did not have restraints. Forgetting/not checking the CRD was the most common reason that emerged from the unprompted "other" category for non-use in both methods, but was much more common in the interview/inspection ( $30 \%$ of reasons given) than the questionnaire (7\%). The focus group interviews identified similar reasons but obtained more specific information on the reasons and context of non-use of CRDs. No relationships were found between the reasons given for non-use of a CRD and other variables such as the type of vehicle driven.

\section{Representativeness}

Demographic data were collected from participants in all methods except the observational survey (table 4). 
Table 3 Details obtained from methods recruiting from supermarket car parks (values are \%)*

\begin{tabular}{|c|c|c|c|}
\hline & $\begin{array}{l}\text { Observational } \\
\text { survey }\end{array}$ & $\begin{array}{l}\text { Interview/ } \\
\text { inspection }\end{array}$ & $\begin{array}{l}\text { Self } \\
\text { administered } \\
\text { questionnaire }\end{array}$ \\
\hline Drivers & $(n=278)$ & $(n=207)$ & $(n=148)$ \\
\hline Sex: \% female & 69 & 66 & 60 \\
\hline Seatbelt used & 88 & 94 & 98 \\
\hline \multicolumn{4}{|l|}{ Relationship to child } \\
\hline Parent & & 89 & 92 \\
\hline Grandparent & & 4 & 7 \\
\hline Non-family member & & 5 & 0 \\
\hline Vehicle type & $(n=278)$ & $(n=207)$ & $(n=148)$ \\
\hline Sedan & 58 & 49 & 46 \\
\hline Station wagon & 17 & 19 & 18 \\
\hline Hatchback & 10 & 17 & 8 \\
\hline Minivan/van & 8 & 3 & 2 \\
\hline Four wheel drive & 2 & 4 & 16 \\
\hline $\begin{array}{l}\text { Utility vehicle } \\
\text { (pick-up) }\end{array}$ & 1 & 1 & 5 \\
\hline Japanese imports & & 37 & 43 \\
\hline CRDs: details & & $(n=207) \ddagger$ & $(n=148) \pm$ \\
\hline \multicolumn{4}{|l|}{ Ownership } \\
\hline Parents & & 75 & 75 \\
\hline $\begin{array}{l}\text { Organisations } \\
\text { that hire CRDs }\end{array}$ & & 10 & 7 \\
\hline Family or friends & & 5 & 7 \\
\hline Missing & & 10 & 11 \\
\hline \multicolumn{4}{|l|}{$\begin{array}{l}\text { Driver learnt to } \\
\text { install from }\end{array}$} \\
\hline $\begin{array}{l}\text { Manufacturer's } \\
\text { manual }\end{array}$ & & 46 & 53 \\
\hline $\begin{array}{l}\text { Community } \\
\text { organisations }\end{array}$ & & 18 & 13 \\
\hline $\begin{array}{l}\text { Figuring out } \\
\text { on own }\end{array}$ & & 14 & 18 \\
\hline $\begin{array}{l}\text { Family member } \\
\text { or friend }\end{array}$ & & 11 & 5 \\
\hline \multicolumn{4}{|l|}{ Frequency of removal } \\
\hline COnce a week & & 50 & 45 \\
\hline Once a week & & 13 & 8 \\
\hline $\begin{array}{l}\text { Several times } \\
\text { a week }\end{array}$ & & 19 & 11 \\
\hline Daily & & 12 & 11 \\
\hline \multirow{2}{*}{\multicolumn{4}{|c|}{$\begin{array}{l}\text { Perception of fitting } \\
\text { CRD in vehicle }\end{array}$}} \\
\hline & & & \\
\hline Very easy & & 62 & 65 \\
\hline Somewhat easy & & 22 & 24 \\
\hline \multicolumn{4}{|l|}{$\begin{array}{l}\text { Perception of placing } \\
\text { child in CRD }\end{array}$} \\
\hline Very easy & & 66 & 62 \\
\hline Somewhat easy & & & \\
\hline Children & $(n=278) \dagger$ & $(n=326)$ & $(n=253)$ \\
\hline \multicolumn{4}{|l|}{ Age (estimates only) } \\
\hline 0-11 months & 30 & 17 & 8 \\
\hline $1-4$ years & 56 & 56 & 42 \\
\hline $5-8$ years & 12 & 21 & 50 \\
\hline Missing & 2 & 6 & 0 \\
\hline \multicolumn{4}{|l|}{ Sex (estimates only) } \\
\hline Male & 39 & 48 & 54 \\
\hline Female & 35 & 44 & 45 \\
\hline Missing & 26 & 8 & 1 \\
\hline CRDs in vehicles & $(n=278) \dagger$ & $(n=326)$ & \\
\hline \multicolumn{4}{|l|}{ Position in car } \\
\hline Front left & 24 & 16 & \\
\hline Left rear & 28 & 42 & \\
\hline Centre rear & 12 & 12 & \\
\hline Right rear & 26 & 29 & \\
\hline Missing & 10 & 1 & \\
\hline \multicolumn{4}{|l|}{ Type (most common) } \\
\hline Infant rear facing & 24 & 10 & \\
\hline Child front facing & 30 & 41 & \\
\hline Booster & 31 & 30 & \\
\hline Child in adult belt & 12 & 17 & \\
\hline
\end{tabular}

*Data recorded for responses reaching $5 \%$ or more for at least one of the methods.

†Because of the lack of data on subsequent children in vehicles in the observational survey, only the first child/CRD observed in each vehicle has been included.

flnformation obtained on these items for one CRD in each vehicle only.
Comparisons were made with the reference population described earlier. The results reported are generally consistent with this reference group, with some exceptions. There were more female respondents in all of the methods than in the reference population. Comparing respondents to each method with the reference population showed that respondents to the interview/inspection were the closest demographically for age and education, while those in the questionnaire were slightly older and had slightly higher education levels. A higher proportion of participants in the focus groups was younger and had lower education levels. Ninety eight percent were female. With respect to household income, a higher proportion of the participants in the focus groups had lower incomes than the reference population, a larger proportion of the interview/inspection respondents had higher incomes, and respondents to the questionnaire were similar in this regard to the reference population.

\section{DISCUSSION}

The methods varied with respect to their efficiency, ability to collect necessary data, and representativeness. A key difference was in the ability to collect data.

The observational survey offered a major advantage in efficiency. Data were collected quickly and easily and virtually all vehicles eligible were included. Not all the necessary data were available. Information on demographics and the fitting of the CRDs could not be ascertained and not all of the expected information was captured, especially where there was more than one child in the vehicle. A higher proportion of children in infant CRDs was recorded in this method, possibly because these children were more visible to the observers than other children in the vehicle.

From an efficiency perspective, the interview/inspection took longer to administer per vehicle than the observational survey, but detailed data were captured on drivers and children and CRD use was examined in situ, by trained personnel. The respondents' demographic characteristics were similar to those of the reference population and refusal rates were very low. The level of incorrect use reported in this method was comparable to those reported in previous studies. ${ }^{911} 19$

The self administered questionnaire was efficient to administer, but indicated a potential bias towards older respondents with higher education levels, as has been found previously with this method. ${ }^{26}$ While a previous study suggested that self report surveys of restraint use can be unreliable measures of CRD use, ${ }^{17}$ the results from the questionnaire were comparable to those from the other methods with a few exceptions, the most notable being the age of the children. Using this method in combination with the observational survey would expand the information collected. Neither the questionnaire alone, nor a combined questionnaire/observational survey would allow for inspection of CRDs in situ, nor provide detail on barriers to CRD use.

Conducting focus group interviews was the most effective method for identifying barriers to CRD use. While it was not intended that participants of these groups represent the population of interest, by randomly selecting childcare centres it was hoped that parents recruited would represent a wide range of socioeconomic status. The selection process resulted in almost an entirely female participation, and this bias needs to be addressed. The composition of focus groups can be determined to better represent specific populations of interest if that is required. In the interview/inspection, using CRDs was generally perceived to be easy. Focus group participants differed considerably on this point. This may be due to the different nature of the response sought in a focus group whereas the interview/inspection sought a response within a simple predetermined scale. Such a response would also have been influenced by the prior 


\begin{tabular}{|c|c|c|c|c|c|c|}
\hline & \multicolumn{2}{|c|}{$\begin{array}{l}\text { Dunedin } \\
\text { population } \\
20-44 \text { years* }\end{array}$} & $\begin{array}{l}\text { Observation } \\
\text { survey } \\
\text { ( } n=278)\end{array}$ & \multirow[t]{2}{*}{$\begin{array}{l}\text { Interview/inspection } \\
(n=207)\end{array}$} & \multirow[t]{2}{*}{$\begin{array}{l}\text { Self administered } \\
\text { questionnaire } \\
\text { ( } n=148 \text { ) }\end{array}$} & $\begin{array}{l}\text { Focus group } \\
(n=45)\end{array}$ \\
\hline \multicolumn{5}{|l|}{ Ethnicity } & & \\
\hline Maori & 6 & & - & 6 & 4 & 4 \\
\hline NZ European & 88 & & - & 85 & 90 & 87 \\
\hline Pacific & 2 & & - & 2 & 1 & 0 \\
\hline Other/missing & 5 & & - & 7 & 6 & 9 \\
\hline Total & 101 & & - & 100 & 100 & 100 \\
\hline \multicolumn{7}{|l|}{ Sex } \\
\hline Male & 47 & & 31 & 30 & 39 & 2 \\
\hline Female & 53 & & 69 & 66 & 60 & 98 \\
\hline Missing & - & & 0 & 4 & 1 & 0 \\
\hline Total & 100 & & 100 & 100 & 100 & 100 \\
\hline \multicolumn{7}{|l|}{ Age (years) } \\
\hline Census & & Survey & & & & \\
\hline $15-19$ & - & $17-20$ & & 2 & 1 & 0 \\
\hline $20-24$ & 27 & $21-25$ & & 14 & 6 & 9 \\
\hline $25-29$ & 17 & $26-30$ & & 21 & 12 & 24 \\
\hline $30-34$ & 17 & $31-35$ & & 30 & 26 & 40 \\
\hline $35-39$ & 19 & $36-40$ & & 22 & 35 & 22 \\
\hline $40-44$ & 19 & $41-45$ & & 5 & 14 & 4 \\
\hline $45-49$ & - & $46-50$ & & 2 & 1 & 0 \\
\hline $50+$ & - & $51+$ & & 3 & 5 & 0 \\
\hline Total & 100 & & & 100 & 100 & 100 \\
\hline \multicolumn{7}{|l|}{ Education } \\
\hline None & 14 & & & 15 & 10 & 9 \\
\hline Secondary & 39 & & & 38 & 35 & 47 \\
\hline Tertiary & 21 & & & 22 & 24 & 24 \\
\hline University & 19 & & & 25 & 31 & 20 \\
\hline Unstated & 7 & & & & & \\
\hline Total & 100 & & & 100 & 100 & 100 \\
\hline \multicolumn{7}{|l|}{$\begin{array}{l}\text { Household income } \\
\text { (Dunedin population, } \\
\text { all ages) (\$) }\end{array}$} \\
\hline $1-10000$ & 6 & & & 3 & 3 & 0 \\
\hline $10001-15000$ & 10 & & & 6 & 8 & 18 \\
\hline $15001-20000$ & 9 & & & 7 & 6 & 9 \\
\hline $20001-25000$ & 6 & & & 7 & 5 & 9 \\
\hline $25001-30000$ & 9 & & & 9 & 9 & 11 \\
\hline $30001-40000$ & 10 & & & 10 & 14 & 29 \\
\hline $40001-50000$ & 9 & & & 15 & 14 & 13 \\
\hline $50001-70000$ & 13 & & & 10 & 14 & 2 \\
\hline $70001-100000$ & 7 & & & 15 & 16 & 7 \\
\hline $100001+$ & 6 & & & 7 & 5 & 0 \\
\hline Missing/unstated & 15 & & & 12 & 6 & 2 \\
\hline Total & 100 & & & 100 & 100 & 100 \\
\hline
\end{tabular}

knowledge regarding the topic among focus group participants.

Some modification of the questions would improve the data collection. For example, one question imposed a six month time frame for recall on the non-use of a CRD. A high

\section{Key points}

- The three methods piloted using randomly selected sites and times were generally representative of the population of interest.

- An interview with the driver of the vehicle and a close inspection of the child restraint device used provided the most reliable data on the extent and nature of incorrect use of CRDs.

- Focus groups with a variety of CRD users provided greater detail on the barriers to CRD use than any other method piloted in this study.

- These methods need to be further piloted in different cultures and different geographical settings. proportion of respondents considered the question did not apply to them. In comparison, participants of focus groups were not confined to this time period and were forthcoming about incidents of non-use of CRDs. This may, however, simply reflect the open nature of the focus group interviews in which a non-judgmental environment can be developed. In future, this question should be asked without a defined time frame.

Other issues require consideration before undertaking a national study. The ethnicity of the respondents in the pilot study does not reflect that of the New Zealand population that has, for example, a higher proportion of Pacific peoples than does the Dunedin population. Further research is needed to consider the preferred methods in light of their appropriateness particularly for obtaining information from Maori and Pacific populations.

No research has been reported on barriers to CRD use in New Zealand since the mid-1980s. The introduction of compulsory CRD use laws in 1994 is likely to have increased CRD use, but unlikely to have removed the barriers to their use. While two methods are identified here as the most appropriate for obtaining necessary data efficiently, they were piloted with a predominantly New Zealand European sample, in a small city. Consideration of issues related to 
using these methods in large urban environments would be essential before undertaking a national study.

\section{CONCLUSION}

The interview/inspection method was the preferred option for providing reliable data on the extent and nature of incorrect use of CRDs. Similarly, conducting focus groups with a variety of CRD users provided greater detail on the barriers to CRD use than any other method.

\section{ACKNOWLEDGEMENTS}

The authors thank Dr Dorothy Begg and Ms Sue Campbell for their comments on a draft of this paper. The IPRU programme is funded by the Health Research Council of New Zealand and the Accident Compensation Corporation (ACC). Dr John Wren was funded by a Health Research Council Post-doctoral Fellowship and financial assistance was provided through an Otago Research Grant.

\section{Authors' affiliations}

J C Simpson, J Wren, D J Chalmers, S C R Stephenson, Injury Prevention Research Unit, University of Otago, Dunedin, New Zealand

\section{REFERENCES}

1 United Nations Children's Fund. A league table of child deaths by injury in rich nations. Innocenti report card No 2. Florence, Italy: United Nations Children Fund, 2001.

2 Kypri K, Chalmers D, Langley J. Child injury mortality in New Zealand 198695. J Pediatr Child Health 2000;36:431-9.

3 Land Transport Safety Authority. Child restraint statistics (http:// www.ltsa.govt.nz/research/belts3.html). Wellington, NZ: New Zealand Land Transport Safety Authority, March 2001.

4 Bull MJ, Stroup KB, Gerhart S. Misuse of car safety seats. Pediatrics 1988;81:98-101.

5 Margolis LH, Wagenaar AC, Molnar U. Use and misuse of automobile child restraint devices. American Journal of Diseases of Children 1992;146:361-6.

6 National Highway Transportation Safety Administration. Observed patterns of misuse of child safety seats. Traffic technical report No 133. Washington, DC: US Department of Transportation, 1996.

7 Decina LE, Knoebel KY. Child safety seat misuse patterns in four states. Accid Anal Prev 1997;29:125-32.
8 Brown B, Pedder J, Pasco D. Existing child restraint use data: does it define the problem? 42nd annual AAAM world conference proceedings. Des Plaines, IL: Association for the Advancement of Automotive Medicine, 1998:15-28.

9 National Highway Transportation Safety Administration. Final economic assessment: child restraint systems, child restraint anchorage systems. Washington, DC: US Department of Transportation, 1999.

10 Wikman J. Child restraint advice and fitting service in Queensland. Brisbane: Royal Automobile Club of Queensland, 1999.

11 Eby DW, Kostyniuk LP. A statewide analysis of child safety seat use and misuse in Michigan. Accid Anal Prev 1999:31:555-66.

12 Geddis DC. Children in cars. Results of an observational study in New Zealand. N Z Med J 1979;90:468-71.

13 Geddis DC, Speirs GF. Why parents do not provide automobile restraints for their children. Australian Paediatric Journal 1980;16:114-16.

14 Geddis DC, Pettengell R. Parent education: its effect on the way children are transported in cars. N Z Med J 1982;95:314-16.

15 Geddis DC, Appleton IC. Establishment and evaluation of a pilot child car seat rental scheme in New Zealand. Pediatrics 1986;77:167-72.

16 Geddis DC, Appleton IC. The establishment of child car seat rental schemes in New Zealand. Road traffic safety seminar papers. Wellington, NZ: Land Transport Safety Authority, 1984;2:243-62.

17 Webb GR, Bowman JA, Sanson-Fisher RW. Studies of child safety restraint use in motor vehicles-some methodological considerations. Accid Anal Prev 1988;20:109-15.

18 United States National Highway Traffic Safety Administration. Federal motor vehicle safety standards; child restraint systems; child restraint anchorage systems. Federal register 49 CFR parts 571 and 596. Washington, DC: US Department of Transportation, 1999.

19 Margolis LH, Wagenaar AC, Molnar $\mathrm{L}$. Recognising the common problems of child automobile restraint misuse. Pediatrics 1988;81:717-20.

20 Land Transport Safety Authority. New Zealand motor vehicle registration statistics 1999. Wellington, NZ: Land Transport Safety Authority, 2000.

21 Green J, Hart L. Children's views of accident risks and prevention: a qualitative study. Inj Prev 1998;4:14-21.

22 Miles MB, Huberman MA. Qualitative data analysis: an expanded source book. California: Sage, 1994

23 Green J, Hart L. The impact of context on data. In: Barbour RS, Kitzinger J, eds. Developing focus group research. London: Sage, 1999.

24 Statistics New Zealand. 2001 Census (http://www.stats.govt.nz/ census.htm). Wellington, NZ: Statistics New Zealand, December 2002

25 Madsen CP. Safety of children in cars. Safety systems, their use and misuse possibilities. Ugeskr Laeger 1991;153:1037-40.

26 Abramson JH. Survey methods in community medicine. 4th Ed. New York: Churchill Livingstone, 1990:166.

27 Webb GR, Sanson-Fisher RW, Bowman JA. Psychosocial factors related to parental restraint of pre-school children in motor vehicles. Accid Anal Prev 1988;20:87-94.

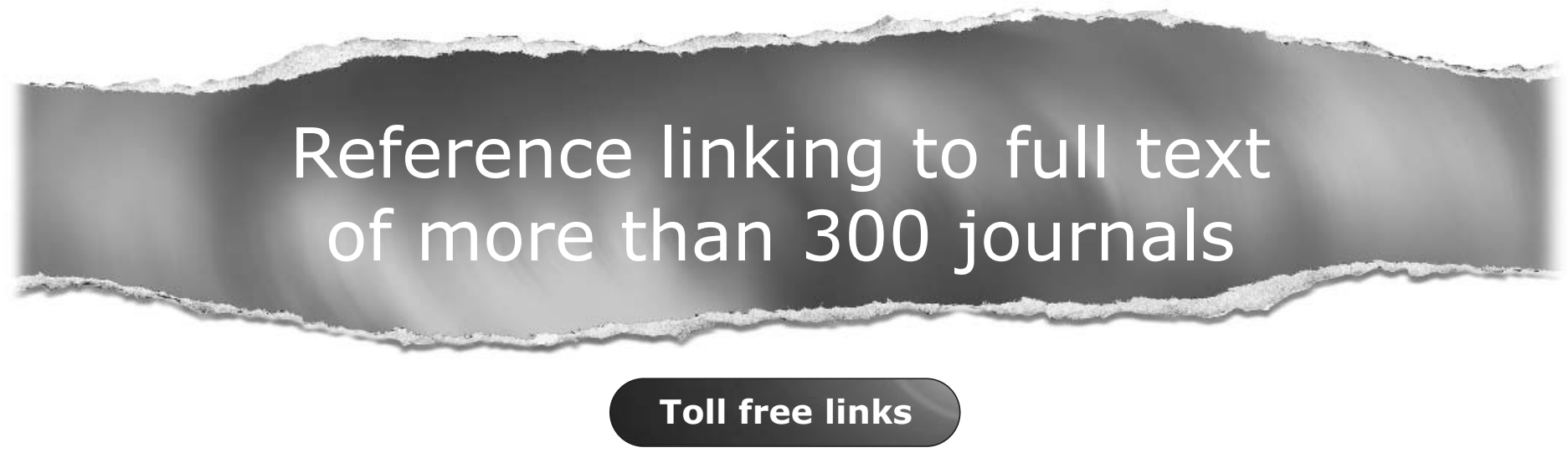

You can access the FULL TEXT of articles cited in Injury Prevention online if the citation is to one of the more than 300 journals hosted by HighWire (http://highwire.stanford.edu) without a subscription to that journal. There are also direct links from references to the Medline abstract for other titles. 